\title{
カルボン酸，エステル，酸無水物などと二，三の アルケニルマグネシウム＝ブロ之ドの反応
}

\author{
渡辺昭次 - 藤田力 須賀恭一・斎藤紀雄 \\ 千葉大学工学部工業化学科 (千葉市弥生町)
}

\author{
The Reaction of Carboxylic Acids, Esters, and Acid Anhydrides \\ with Various Alkenylmagnesium Bromides \\ Shōji Watanabe, Tsutomu Fujita, Kyōichi Suga, \\ and Norio SAItō \\ Department of Applied Chemistry, Faculty of Engineering, \\ Chiba University (Yayoicho, Chiba)
}

\begin{abstract}
The reaction of carboxylic acids, esters, and acid anhydrides with alkenylmagnesium bromide yields mixtures of alkenones and alkenols as the main products. The reaction of vinylmagnesium bromide gives similar results to that of vinylmagnesium chloride. The reactions of isopropenylmagnesium bromide or 1-propenylmagnesium bromide with acids, esters, and anhydrides produce mainly isopropenyl ketones.
\end{abstract}

\section{1 緒言}

特殊なグリニャール試薬であるアルケニルマグネシウ ム=クロリドと種々の化合物との反応は広く研究されて おり1，著者らもカルボン酸とその誘導体との反応につ いて報告した ${ }^{2), 3) 。 ア ル ケ ニ ル マ ク ゙ ネ シ ウ ム=フ ゙ ロ ミ ト ゙ と ~}$ の反応についてはエステルとの反応による 1-ビニル-2プロペンー1-オールを生成することは報告されでいる が1)，アルケニルマグネシウム=ブロミドと種々のカル ボン酸及びその誘導体との反応については詳細に研究さ れていないようである。本研究ではビニルマグネシウム= ブロミド，イソプロペニルマグネシウム=ブロミド，1プロペニルマグネシウム=ブロミドなどとカルボン酸及 びその二，三の誘導体との反応について検討し，主反応 生成物として不飽和ケトン類の混合物が得られることを 知った。

\section{2 実験の 部}

\section{$2 \cdot 1$ 吉草酸メチルとビニルマグネシウム=ブロミドの} 反応

ビニルマグネシウムニブロミドのテトラヒドロフラン (THF) 溶液は，マグネシウム $5.59 \mathrm{~g}(0.233 \mathrm{~mol})$, ビ ニルマグネシウム $25 \mathrm{~g}(0.233 \mathrm{~mol}), \operatorname{THF}(100 \mathrm{ml})$ か ら常法によって調製した。これに吉草酸メチル $(6.81 \mathrm{~g}$, $0.058 \mathrm{~mol})$ を室温で滴下し，そのまま $5 \mathrm{~h}$ かくはんしさ
らに一晚放置した。反応混合物を $0^{\circ} \mathrm{C}$ に保ちながら塩 化アンモニウム水溶液を加えて加水分解しイソプロピル エーテルで抽出した。エーテル溶液は水洗後, 硫酸ナト リウム（無水物）で乾燥した。エーテルを留去後, 残留 物を減圧蒸留して次の留分を得た。留分 (i) : bp 70 $80^{\circ} \mathrm{C} / 10 \mathrm{mmHg}$, 収量 $1.5 \mathrm{~g}$; 留分 (ii) : bp $80 \sim 90^{\circ} \mathrm{C} /$ $10 \mathrm{mmHg}$, 収量 $1.5 \mathrm{~g}$ 。留分（i）は 3-ブチル $-1,4-$ ペンタジェン-3-オール (1) (75\%) と 1-ノネン-5-オ ン (2) $(25 \%)$ の混合物であった。留分（ii）注化合物

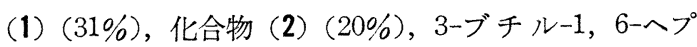
タジェン-3-オール (3) (39\%), 未確認物質 (10\%) の 混合物であった。化合物 (1)（2）(3) は標準品) と比 較することにより確認した。他のエステル, 酸無水物, アシルクロリドなどとの反応も同様汇行った（Table1)。

2.2 オクタン酸とイソプロペニルマグネシウム ミドとの反応

イソプロペニルマグネシウム=ブロミドの THF 溶液 は，マグネシウム $7.3 \mathrm{~g}(0.3 \mathrm{~mol})$, イソプロペニル=ブ ロミド4) $36.3 \mathrm{~g}(0.3 \mathrm{~mol})$, THF (100 ml) から常法に よって調製した。オクタン酸 $(10.8 \mathrm{~g}, 0.075 \mathrm{~mol})$ の $\mathrm{THF}(10 \mathrm{ml})$ 溶液を室温で滴下し, さらに室温で $4 \mathrm{~h}$ くはん後, 一夜放置した。常法通り処理して次の留分を 得た。留分 (i ) : bp $90 \sim 100^{\circ} \mathrm{C} / 2 \mathrm{mmHg}$, 収量 $2.5 \mathrm{~g}$; 留分（ii）: bp $100 \sim 110^{\circ} \mathrm{C} / 2 \mathrm{mmHg}$, 収量 $6.5 \mathrm{~g}$ 。2-メ 
チル-1-デセン-3-オン (4) 溜分 (i) から，2,4-ジ メチル-1ードデセン-5-オン (5) は留分 (ii) から GLC によってそれぞれ単離した。これらの生成物は次の諸性 質を示した。

(4) : IR $\left(\mathrm{cm}^{-1}\right): 925,1680 ; \operatorname{NMR}(\delta, \mathrm{ppm}): 0.90$ $\left(t, \mathrm{~J}=6.0 \mathrm{~Hz}, 3 \mathrm{H}, \mathrm{CH}_{3}\right), 1.20 \sim 1.30(\mathrm{~m}, 10 \mathrm{H}$, $\left.-\mathrm{CH}_{2}-\right), 1.80\left(s, 3 \mathrm{H}, \quad \underline{\mathrm{H}}_{3} \mathrm{C}=\right), 2.55(t, \mathrm{~J}=7.5 \mathrm{cps}$, $\left.2 \mathrm{H},-\mathrm{CH}_{2}-\mathrm{CO}\right), 5.60(s, 1 \mathrm{H}, \mathrm{C}=\mathrm{C} \underline{\mathrm{H}}$, trans $), 5.80$ $(s, 1 \mathrm{H}, \mathrm{C}=\mathrm{CH}, c i s)$; $\mathrm{UV}\left(\mathrm{CH}_{3} \mathrm{OH}\right): \lambda_{\max } 220 \mathrm{~nm}$, $\varepsilon 8830$ 。

(5) : IR : 890, 1710; NMR : $0.9(t, \mathrm{~J}=6.0 \mathrm{~Hz}, 3 \mathrm{H}$, $\left.\mathrm{C}_{3} \mathrm{CH}_{2}\right), 1.0\left(d, \mathrm{~J}=7.0 \mathrm{~Hz}, 3 \mathrm{H}, \mathrm{CH}_{3} \mathrm{CHCO}\right), 1.16$ $\sim 1.30\left(\mathrm{~m}, \mathrm{~s}, 10 \mathrm{H},-\mathrm{C}_{2}{ }_{2}-\right), 1.68\left(s, 3 \mathrm{H}, \mathrm{Cl}_{3} \mathrm{C}=\right), 1.90$ $\sim 2.75\left(m, 5 \mathrm{H}, \mathrm{CH}_{2} \mathrm{C}=, \mathrm{CHCO}, \mathrm{COCH}_{2}\right), 4.6(d$, $\mathrm{J}=4.0 \mathrm{~Hz}, 2 \mathrm{H}, \mathrm{CH}_{2}=\mathrm{C}$ )。化合物 (4)，(5) の元素分析 值 $(\mathrm{C}, \mathrm{H})$ は計算值と一致した。

\section{$2 \cdot 3$ 酪酸メチルと 1-プロペニルマグネシウム}

\section{ミドの反応}

窒素気流下，水冷下で常法によって調製した 1-プロ ペニルマグネシウムシブロミド $(0.15 \mathrm{~mol})$ の THF 溶液 $(50 \mathrm{ml})$ に，酪酸メチル $(4.1 \mathrm{~g}, 0.04 \mathrm{~mol})$ を滴下し た。反応混合物を $6 \mathrm{~h}$ 還流後, 常法通り処理して次の 各留分を得た。留分 (i) : bp $39 \sim 51^{\circ} \mathrm{C} / 2 \mathrm{mmHg}$, 収量 $0.8 \mathrm{~g}$; 留分(ii): bp $51 \sim 54^{\circ} \mathrm{C} / 2 \mathrm{mmHg}$, 収量 $4.8 \mathrm{~g}$; 留 分 (iii): bp $95 \sim 131^{\circ} \mathrm{C} / 2 \mathrm{mmHg}$, 収量 $0.4 \mathrm{~g}$ 。留分(i) から 6-メチル-7-ノネン-4-オン(6)を GLC で単離し た。このものは次の性質を示した。IR：966, 1710；N MR: $0.8\left(t, \mathrm{~J}=6.5 \mathrm{~Hz}, 3 \mathrm{H}, \mathrm{CH}_{3}-\right), 0.9(d, \mathrm{~J}=6.00$ $\left.\mathrm{Hz}, 3 \mathrm{H}, \mathrm{CH}_{3}\right), 1.3 \sim 1.5\left(m, 2 \mathrm{H},-\mathrm{CH}_{2}-\right), 1.31 \sim$ $1.70(m, 1 \mathrm{H},-\mathrm{CH}) ; 1.7\left(d, \mathrm{~J}=5.0 \mathrm{~Hz}, 3 \mathrm{H}, \mathrm{CH}_{3}\right.$ $-\mathrm{C}=), 2.2\left(d, J=8.0 \mathrm{~Hz}, 4 \mathrm{H},-\mathrm{CH}_{2} \mathrm{COCH}_{2}-\right), 5.1 \sim$ $5.6(m, 2 \mathrm{H},-\mathrm{CH}=\mathrm{CH}-) ; \mathrm{MS}(m / e): \mathrm{M}^{+}=154$ 。元 素分析值 $(\mathrm{C}, \mathrm{H})$ は計算値と一致した。

\section{3 結果と考察}

著者らはさきに脂肪族カルボン酸及びその誘導体とビ ニルマグネシウムニクロリドとの反応で主反応生成物 と してビニルケトン体とジビニルアルコール体の混合物を 与えることを報告しだ2),3)。ビニルマグネシウム=ブロ ミドとカルボン酸などとの反応でもビニルマグネシウ ム=クロリドとほとんど同じ生成物を与える。例えば吉 草酸メチルと THF 中で調製したビニルマグネシウム= ブロミドとの反応からは（1），(2)，（3）などの混合物 が得られた。また酸無水物との反応でもビニルマグネシ ウムニクロリドと同様の生成物を与える。しかしアシル クロリドとの反応や塩化銅 (I) の存在下での反応で, ビニルマグネシウムニクロリドの場合には好收率で得ら れるジケトン類の收率仗きわ加て低かった。これらの結

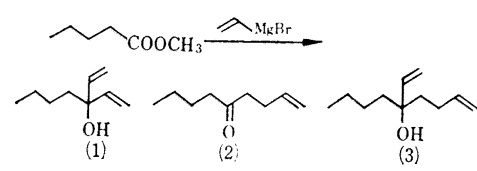

Table-1 The reaction of carboxylic acid derivatives with vinylmagnesium bromide.

\begin{tabular}{|c|c|c|}
\hline $\begin{array}{l}\text { Acid } \\
\text { derivatives }\end{array}$ & Composition of products & $\begin{array}{l}\text { Yield } \\
(\%)\end{array}$ \\
\hline \multirow{3}{*}{$\begin{array}{l}\text { Methyl } \\
\text { valerate }\end{array}$} & 3-Butyl-1,4-pentadien-3-ol & 23 \\
\hline & 1-Nonen-5-one & 10 \\
\hline & 3-Butyl-1,6-heptadien-3-ol & 9 \\
\hline $\begin{array}{l}\text { Methyl } \\
\text { benzoate }\end{array}$ & 1-Phenyl-4-penten-1-one & 40 \\
\hline \multirow{4}{*}{$\begin{array}{l}\text { Methyl } \\
\text { cyclohexyl- } \\
\text { carboxylate }\end{array}$} & 1-Cyclohexyl-2-propen-1-one & 3 \\
\hline & 3-Cyclohexyl-1,4-pentadien-3-ol & 6 \\
\hline & 1-Cyclohexyl-4-penten-1-one & 58 \\
\hline & 3-Cyclohexyl-1,6-heptadien-3-ol & 8 \\
\hline \multirow{4}{*}{$\begin{array}{l}\text { Isobutyric } \\
\text { anhydride }\end{array}$} & 3-Isopropyl-1,4-pentadien-3-ol & 8 \\
\hline & 2-Methyl-6-hepten-3-one & 8 \\
\hline & $\begin{array}{l}\text { 4-Allyl-2,8-dimethyl-3, 7-nonane- } \\
\text { dione }\end{array}$ & 20 \\
\hline & $\begin{array}{l}\text { 6-Allyl-7-hydroxy-7-isopropyl- } \\
\text { 2-methyl-8-nonen-3-one }\end{array}$ & 5 \\
\hline \multirow{4}{*}{$\begin{array}{l}\text { Butyric } \\
\text { anhydride }\end{array}$} & $3-V$ inyl-1-hexen-3-ol & 7 \\
\hline & 7-Octen-4-one & 7 \\
\hline & 5-Allyl-4, 8-undecanedione & 21 \\
\hline & $\begin{array}{l}\text { 7-Allyl-8-hydroxy-8-propyl } \\
\text {-9-decen-4-one }\end{array}$ & 7 \\
\hline \multirow{2}{*}{$\begin{array}{l}\text { Methyl } \\
\text { isobutyrate* }\end{array}$} & 2-Methyl-6-hepten-3-one & 3 \\
\hline & 2,9-Dimethyl-3,8-decanedione & Tr. \\
\hline \multirow{2}{*}{$\begin{array}{l}\text { Butyryl } \\
\text { chloride }\end{array}$} & 7-Octen-4-one & 2 \\
\hline & 3-Propyl-1, 4-pentadien-3-ol & $\operatorname{Tr}$ \\
\hline
\end{tabular}

* In this case, the reaction was performed in the presence of $\mathrm{CuCl}$.

果を Table-1 にまとめて示す。

オクタン酸と過剩のイソプロペニルマグネシウム ロミドとの反応を試みたところ $1 \mathrm{~mol}$ のグリニャール

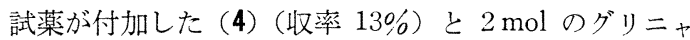
一ル試薬が付加した（5）(49\%)の混合物が得られた。 同様にその他の酸, エステル，酸無水物からイソプロペ ニルケトン類が生成するが (Table-2 4)，イソプロペ ニルマグネシウムニブロミドとの反応からは，ビニルマ グネシウムニクロリドと違ってアルケノール類什得られ なかった。

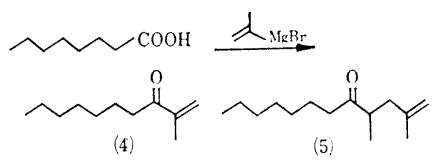


Table-2 The reaction of carboxylic acids with isopropenylmagnesium bromide.

\begin{tabular}{|c|c|c|c|}
\hline $\begin{array}{c}\text { Carboxylic } \\
\text { acid }\end{array}$ & Composition of products & $\begin{array}{l}\text { Yield } \\
(\%)\end{array}$ & $\begin{array}{l}\mathrm{bp} \\
\left({ }^{\circ} \mathrm{C} /\right. \\
\mathrm{mmHg})\end{array}$ \\
\hline \multirow{2}{*}{$\begin{array}{l}\text { Butyric } \\
\text { acid }\end{array}$} & 2-Methyl-1-hexen-3-one & 10 & $88 / 38$ \\
\hline & 5,7-Dimethyl-7-octen-4-one & 35 & $88 / 38$ \\
\hline \multirow{2}{*}{$\begin{array}{l}\text { Isobutyric } \\
\text { acid }\end{array}$} & 2,4-Dimethyl-1-penten-3-one & 9 & $45 / 2$ \\
\hline & $\begin{array}{l}\text { 2, 4,6-Trimethyl-6-hepten } \\
\text {-3-one }\end{array}$ & 33 & $45 / 2$ \\
\hline \multirow{2}{*}{$\begin{array}{l}\text { Valeric } \\
\text { acid }\end{array}$} & 2-Methyl-1-hepten-3-one & 15 & $60 / 2$ \\
\hline & 2,4-Dimethyl-1-nonen-5-one & 45 & $60 / 2$ \\
\hline \multirow{2}{*}{$\begin{array}{l}\text { Isovaleric } \\
\text { acid }\end{array}$} & 2,5-Dimethyl-1-hexen-3-one & 4 & $55 / 2$ \\
\hline & $\begin{array}{l}\text { 2,5,7-Trimethyl-7-octen } \\
\text {-4-one }\end{array}$ & 50 & $55 / 2$ \\
\hline \multirow{2}{*}{$\begin{array}{l}\text { Hexanoic } \\
\text { acid }\end{array}$} & 2-Methyl-1-octen-3-one & 11 & $109 / 17$ \\
\hline & 2,4-Dimethyl-1-decen-5-one & 41 & $109 / 17$ \\
\hline \multirow{2}{*}{$\begin{array}{l}\text { Octanoic } \\
\text { acid }\end{array}$} & 2-Methyl-1-decen-3-one & 13 & $100 / 2$ \\
\hline & $\begin{array}{l}\text { 2, 4-Dimethyl-1-dodecen } \\
\text {-5-one }\end{array}$ & 49 & $100 / 2$ \\
\hline \multirow[t]{2}{*}{$\begin{array}{l}\text { benzoic } \\
\text { acid }\end{array}$} & $\begin{array}{l}\text { 2-Methyl-1-phenyl } \\
\text {-2-propen-1-one }\end{array}$ & 32 & $102 / 2$ \\
\hline & $\begin{array}{l}\text { 2, 4-Dimethyl-1-phenyl } \\
\text {-4-penten-1-one }\end{array}$ & 33 & $102 / 2$ \\
\hline \multirow[t]{2}{*}{$\begin{array}{l}p \text {-Toluic } \\
\text { acid }\end{array}$} & $\begin{array}{c}\text { 2-Methyl-1-( } p \text {-tolyl }) \\
\text {-2-propen-1-one }\end{array}$ & 33 & $99 / 2$ \\
\hline & $\begin{array}{c}\text { 2, 4-Dimethyl-1- }(p \text {-tolyl }) \\
\text {-4-penten-1-one }\end{array}$ & 35 & $110 / 2$ \\
\hline \multirow{2}{*}{$\begin{array}{l}\text { Cyclohe- } \\
\text { xanecarbo- } \\
\text { xylic acid }\end{array}$} & $\begin{array}{l}\text { 1-Cyclohexyl-2-methyl } \\
\text {-2-propen-1-one }\end{array}$ & 6 & $85 / 2$ \\
\hline & $\begin{array}{l}\text { 1-Cyclohexyl-2,4-dimethyl- } \\
\text { 4-penten-1-one }\end{array}$ & 25 & $85 / 2$ \\
\hline $\begin{array}{l}\text { Citronellic } \\
\text { acid }\end{array}$ & $\begin{array}{l}2,4,7,11 \text {-Tetramethyl- } \\
\text { 1,10-dodecadien-5-one }\end{array}$ & 18 & $100 / 2$ \\
\hline
\end{tabular}

Table-4 The reaction of acid anhydrides with isopropenylmagnesium bromide.

\begin{tabular}{|c|c|c|}
\hline Anhydride & Composition of products & $\begin{array}{c}\text { Yield } \\
(\%)\end{array}$ \\
\hline \multirow{3}{*}{$\begin{array}{l}\text { Butyric } \\
\text { anhydride }\end{array}$} & 2-Methyl-1-hexen-3- & Tr. \\
\hline & 5,7-Dimethyl-7-c & 54 \\
\hline & 5,7-Dimethyl-7-c & 2 \\
\hline \multirow{2}{*}{$\begin{array}{l}\text { Isobutyric } \\
\text { anhydride }\end{array}$} & 2,4-Dimethy & 5 \\
\hline & $2,4,6$-Trimet & 37 \\
\hline \multirow{2}{*}{$\begin{array}{l}\text { Valeric } \\
\text { anhydride }\end{array}$} & 2-Methyl-1-he & 5 \\
\hline & 2,4-Dimethyl-1-nonen-5-one & 67 \\
\hline $\begin{array}{l}\text { Isovaleric } \\
\text { anhydride }\end{array}$ & 2,5,7-Trimethyl-7-octen-4-one & 66 \\
\hline \multirow{2}{*}{$\begin{array}{l}\text { Hexanoic } \\
\text { anhydride }\end{array}$} & 2-Methyl-1-octe & 15 \\
\hline & 2,4-dimethyl-1-decen-5-one & 50 \\
\hline \multirow{2}{*}{$\begin{array}{l}\text { Benzoic } \\
\text { anhydride }\end{array}$} & 2-Methyl-1-phenyl-2-propen-1-one & 2 \\
\hline & $\begin{array}{l}\text { 2, 4-Dimethyl-1-phenyl-4 } \\
\text {-penten-1-one }\end{array}$ & 34 \\
\hline $\begin{array}{l}\text { Cyclohexane- } \\
\text { carboxylic } \\
\text { anhydride }\end{array}$ & $\begin{array}{l}\text { 1-Cyclohexyl-2,4-dimethyl- } \\
\text { 4-penten-1-one }\end{array}$ & 58 \\
\hline
\end{tabular}

Table-3 The reaction of methyl esters with isopropenylmagnesium bromide.

\begin{tabular}{|c|c|c|}
\hline Ester & Composition of products & \begin{tabular}{|c|c|} 
Yield \\
$(\%)$
\end{tabular} \\
\hline \multirow{3}{*}{$\begin{array}{l}\text { Methyl } \\
\text { butyrate }\end{array}$} & 2-Methyl-1-hexen-3-one & 1 \\
\hline & 5,7-Dimethyl-7-octen-4-one & 58 \\
\hline & 5,7-Dimethyl-7-octen-4-ol & 11 \\
\hline \multirow{2}{*}{$\begin{array}{l}\text { Methyl } \\
\text { isobutyrate }\end{array}$} & 2,4-Dimethyl-1-penten-3-one & 3 \\
\hline & $2,4,6$-Trimethyl-6-hepten-3-one & 46 \\
\hline \multirow{2}{*}{$\begin{array}{l}\text { Methyl } \\
\text { valerate }\end{array}$} & 2-Methyl-1-hepten-3-one & 8 \\
\hline & 2,4-Dimethyl-1-nonen-5-one & 77 \\
\hline \multirow{2}{*}{$\begin{array}{l}\text { Methyl } \\
\text { isovalerate }\end{array}$} & 2,5-Dimethyl-1-hexen-3-one & 8 \\
\hline & $2,5,7$-Trimethyl-7-octen-4-one & 60 \\
\hline \multirow{2}{*}{$\begin{array}{l}\text { Methyl } \\
\text { hexanoate }\end{array}$} & 2-Methyl-1-octen-3-one & 12 \\
\hline & 2,4-Dimethyl-1-decen-5-one & 81 \\
\hline $\begin{array}{l}\text { Methyl } \\
\text { benzoate }\end{array}$ & $\begin{array}{l}\text { 2,4-Dimethyl-1-phenyl- } \\
\text { 4-penten-1-one }\end{array}$ & 43 \\
\hline \multirow{2}{*}{$\begin{array}{l}\text { Methyl } \\
p \text {-methyl- } \\
\text { benzoate }\end{array}$} & $\begin{array}{l}\text { 2, 4-Dimethyl-1-( } p \text {-tolyl })-4 \\
\text {-penten-1-one }\end{array}$ & 65 \\
\hline & $\begin{array}{l}\text { 2,4-Dimethyl-1-(p-tolyl)- } \\
\text { 4-penten-1-ol }\end{array}$ & 11 \\
\hline $\begin{array}{l}\text { Methyl } \\
\text { cyclohexyl- } \\
\text { carboxylate }\end{array}$ & $\begin{array}{l}\text { 2, 4-Dimethyl-1-cyclohexyl- } \\
\text { 4-penten-1-one }\end{array}$ & 78 \\
\hline \multirow[t]{2}{*}{$\begin{array}{l}\text { Methyl } \\
\text { citronellate }\end{array}$} & $\begin{array}{l}2,5,9 \text {-Trimethyl-1, 8-decadien- } \\
\text { 3-one }\end{array}$ & 4 \\
\hline & $\begin{array}{l}2,4,7,11 \text {-Tetramethyl- } \\
\text { 1,10-dodecadien-5-one }\end{array}$ & 79 \\
\hline
\end{tabular}

Table-5 The reaction of methyl esters with prop-1-enylmagnesium bromide.

\begin{tabular}{|c|c|c|c|}
\hline Ester & Products & $\begin{array}{c}\text { Yield } \\
(\%)\end{array}$ & $\begin{array}{l}\mathrm{bp} \\
(\mathrm{C} / \\
\mathrm{mmHg})\end{array}$ \\
\hline $\begin{array}{l}\text { Methyl } \\
\text { butyrate }\end{array}$ & 6-Methyl-7-nonen-4-one & 86 & $51 / 2$ \\
\hline $\begin{array}{l}\text { Methyl } \\
\text { isobutyrate }\end{array}$ & 2,5-Dimethyl-6-octen-3-one & 75 & $41 / 2$ \\
\hline $\begin{array}{l}\text { Methyl } \\
\text { valerate }\end{array}$ & 7-Methyl-8-decen-5-one & 75 & $64 / 2$ \\
\hline $\begin{array}{l}\text { Methyl } \\
\text { isovalerate }\end{array}$ & $\begin{array}{l}\text { 2,6-Dimethyl-7-nonen- } \\
\text { 4-one }\end{array}$ & 82 & $58 / 3$ \\
\hline $\begin{array}{l}\text { Methyl } \\
\text { hexanoate }\end{array}$ & 4-Methyl-2-undecen-6-one & 62 & $79 / 2$ \\
\hline $\begin{array}{l}\text { Methyl } \\
\text { benzoate }\end{array}$ & $\begin{array}{l}\text { 3-Methyl-1-phenyl- } \\
\text { 4-hexen-1-one }\end{array}$ & 87 & $109 / 2$ \\
\hline \multirow[t]{2}{*}{$\begin{array}{l}\text { Methyl } \\
p \text {-toluate }\end{array}$} & $\begin{array}{c}\text { 3-Methyl-1-( } p \text {-tolyl)- } \\
\text { 4-hexen-1-one }\end{array}$ & 54 & $105 / 1$ \\
\hline & $\begin{array}{l}\text { 3-Methyl-1-( } p \text {-tolyl)- } \\
\text { 4-hexen-1-ol }\end{array}$ & 7 & $105 / 1$ \\
\hline $\begin{array}{l}\text { Methyl } \\
\text { cyclohexyl- } \\
\text { carboxylate }\end{array}$ & $\begin{array}{l}\text { 1-Cyclohexyl-3-methyl- } \\
\text { 4-hexen-1-one }\end{array}$ & 81 & $87 / 2$ \\
\hline $\begin{array}{l}\text { Methyl } \\
\text { citronellate }\end{array}$ & $\begin{array}{l}\text { 4, 8, 12-Trimethyl- } \\
\text { 2,11-tridecadien-6-one }\end{array}$ & 67 & $100 / 2$ \\
\hline
\end{tabular}




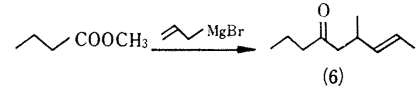

同様に 1-プロペニルマグネシウムニブロミドと酪酸メ チルとの反応を試みたところ主反応生成物として (6) が 得られた。この場合もアルケノール類は得られなかっ た。その他のエステルとの反応を Table-5 に示す。

以上の実験結果から脂肪酸, エステル, 酸無水物など とアルケニルマグネシウム=ブロミドとの反応によって 長鎖のアルケノン類が得られることを知った。これらの
反応は従来知られていない新しい反応であり，これらの 生成物は油化学, 有機合成化学の中間化合物として用い ることができると考えられる。

（昭和 52 年 2 月 17 日受理）

\section{文献}

1) H. Normant, Adv. Org. Chem., 2, 1 (1960)

2) 渡辺昭次, 藤田 力, 須賀恭一, 斎藤紀雄, 油化学, 25, 110 (1976)

3）渡辺昭次, 須賀恭一, 藤田 力, 高橋幸男, 小礒英之, 油化学, 23, 539 (1974)

4) G.B. Bachmann, J. Am. Chem. Soc., 55, 4279(1933) 